\title{
University of Victoria Language Centre Peter Liddell University of Victoria
}

\section{Prologue, Scene 1}

\section{Scene 2}

As the Language Centre looks forward to staging FLEAT III at the University of Victoria, and welcoming the presenters and delegates from Japan, the U.S.A., Canada, and many other parts of the globe, it seems a good opportunity to describe how the Centre grew to this point-the "plot so far":

Fall 1986. Dean's Office. Enter new Lab Academic Director, curious.

Dean of Humanities: "All the language lab equipment that we have-does this stuff really work?"

LAD: "Well, it's mostly reel-to-reel tape recorders, 105 of them, used by students sitting in what looks and feels like modified horse-boxes. UVic acquired them in 1964, just after the university opened. They've been kept from the knacker's yard by virtue of regular, long maintenance procedures. Pedagogically, I'm not sure it does work, and I'm not even sure how much it's used any more."

DoH: "Well see what you can find out and have a look at some of the newer media while you're at it-TV, VCRs, and cassette players-even computers. You've probably got two or three years to come up with recommendations. We need to decide whether to renew or just rip everything out and regain three classrooms for general use."

Spring 1988. LAD on telephone with former DoH, now VPAcademic.

VPAc: "That two-three years I mentioned a few months ago? Time's up. There's a budget possibility in September, if you can make the case by then. After that, not so clear."

Fade.

Cut to 1993. Language Centre. LAD, fax in hand, groans to Lab Coordinator: 
"We have always taken an open-house approach to what we do-partly because we are a publicly-funded facility-but mainly because the value of collaboration with our peers is paramount..."
"Guess what, Mary, another one wanting to know the magic formula. This one's from Thailand:

'Dear Sir.

Our senior administrators have informed us that if we can submit a detailed proposal to them by this Friday, there is a chance that we will be given permission to build a language laboratory on this campus. They have strongly recommended that we model our proposal on the facility at the University of Victoria, which, as you know, they visited last year.

Could you please fax us the following information in the next two days: equipment and software selection criteria, classroom layout, workstation design, electrical and engineering considerations, current and projected usage, and an estimated budget for each item to be purchased."

LC: “\#\%\&* (deleted), Peter. That's three days' work for both of us. Let alone whether anyone should clone anyone else's facility."

... and so it continued. After opening Phase 1 of the new Language Centre in September 1989, we had quickly gained a reputation for a certain quality that's not easy to define.

Since 1989, we have been consulted in some major fashion by dozens of national and international universities and colleges, on lab renovations, design projects and selection criteria, but always (as we did with our Thai partners) under the caveat "It's your lab, your people, your institution. Ours works here, but might not work there." Eventually, we devised a series of files and plans to mail out. Later still, we put some of them on the Web, along with a virtual tour, available at http:/ /web.uvic.ca/langcen/.

We have always taken an open-house approach to what we do-partly because we are a publicly-funded facility-but mainly because the value of collaboration with our peers is paramount, and certainly hard to quantify. Organizing a major conference such as FLEAT is one way of fostering that spirit.

What follows is a snapshot of the growing pains and the people that shaped the Language Centre.

The Prologue no doubt calls up signs that many lab directors will recognize easily: budget windows that threatened to slam shut even as they opened; administrators yearning to give their campus the hi-tech profile; areas of campus that hadn't requested anything more sophisticated than stationery and tape reels for decades now projecting capital expenditures running to six or seven digits-worse yet, we even wanted new staff members to look after the place.

During the spring and summer of 1988, we did get the needs assessment done, made time to educate the educators, 
"If CALL and the two teaching classrooms are the servery, then our research and design center is the magic kitchen."

\section{FLEAT III}

researched and created the pedagogical and methodological rationales, and put them into a package before the critical budget plans were cast.

Then we had the fun of designing workstations (risking the marriage of our former Coordinator, who for three weeks built a cardboard mock-up of a prototype workstation on her marital bed). Niceties like soft lighting and pleasant decor that we now treat as givens created a few skirmishes with parsimonious planners. Open-center, multi-function, learnerfriendly teaching and learning spaces also caused a few raised eyebrows in those days, but they worked from the start. They also eased some instructors into new ways of guiding the students' learning.

What we couldn't expect was staff. But we got them - seven full-time positions-in time for the opening of Phase 1. They are key to our reputation - a team that has gelled into a core of new professionals. Two came with a languages background, most were more the computer type. Now, they all share in the teaching of the technologies, trouble-shoot the quirky parts, and manage the users' FAQs and phobias. Individually, the CALL staff have also developed special expertise in virtual worlds, network management, publishing, and audiovisual recording and editing. With a smorgasbord of over 100 software applications, universal student email, and coursebased Web access as well, there's plenty on the menu.

If CALL and the two teaching classrooms are the servery, then our research and design center is the magic kitchen. Here our two programmers work with faculty, student assistants, and software and hardware companies to concoct CALL software, data-bases, desk-top-published books, as well as web pages by the dozen.

Collectively, the staff of the Centre share considerable experience as conference organizers, as leaders of workshops, and as presenters at conferences. Many of us who are involved in organizing FLEAT III cut our teeth on the CCALL2 conference of 1993. We had just completed Phase 2 of the Language Centre that spring - the two classrooms and the R\&D area. That is also the year we started discussions with IALL and LLA about hosting FLEATIII. By then, our University was convinced, as were we, that "this stuff works." We look forward to learning this August how our colleagues from other places accomplish the same feat. 


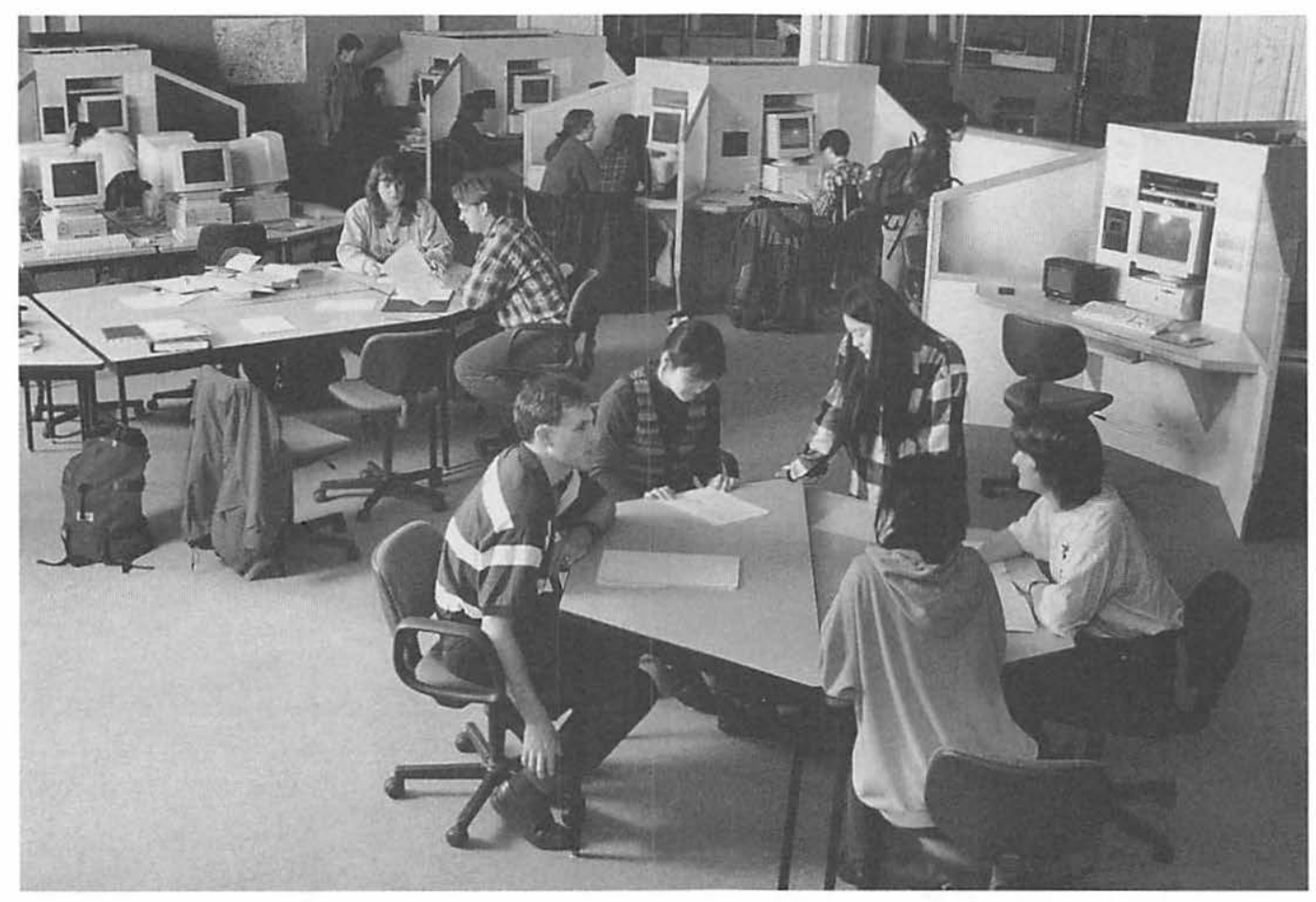

C.A.L.L (Computer-Assisted Language Learning) Facility, Language Centre, University of Victoria. 


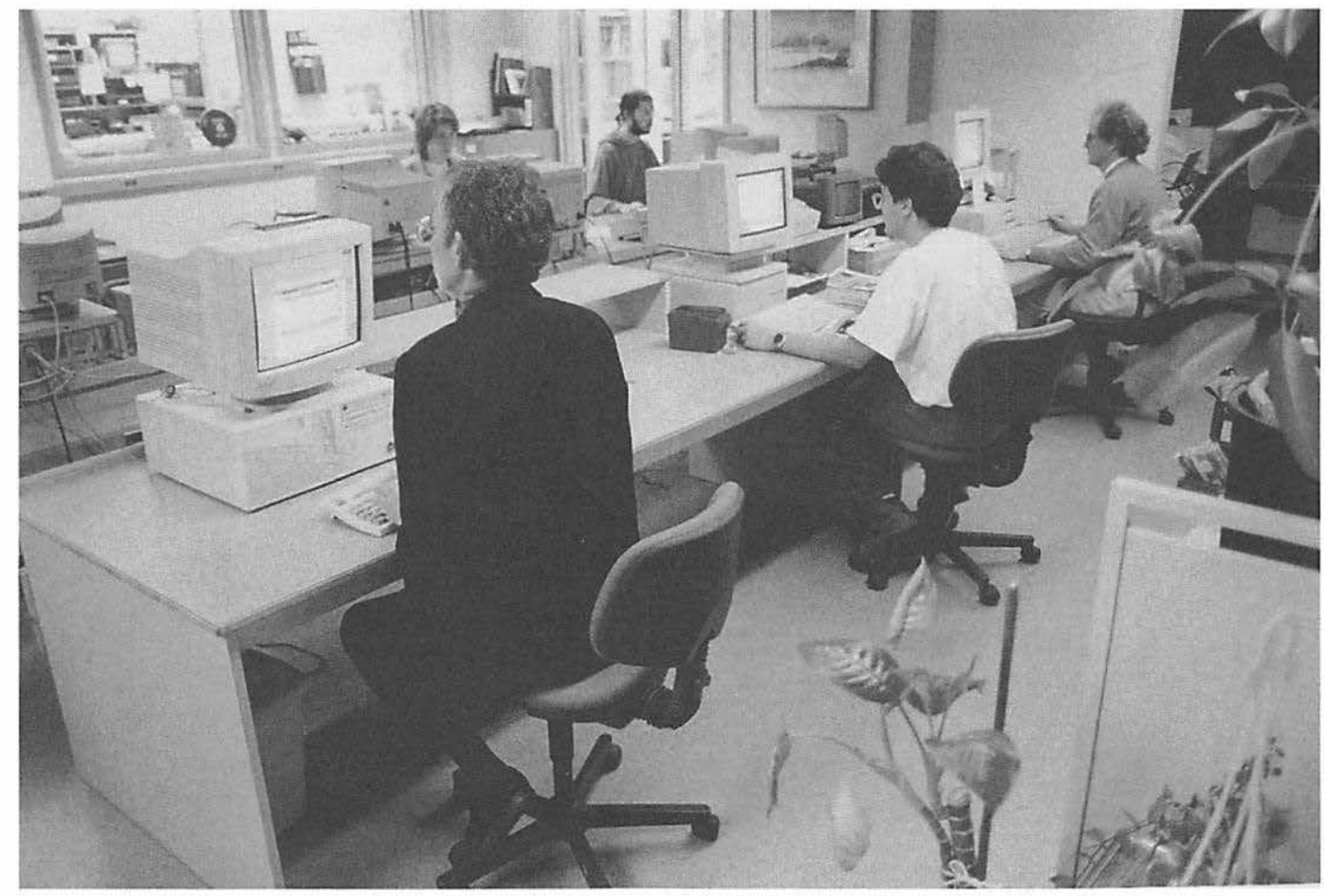

Research and Development Facility, Language Centre, University of Victoria. 


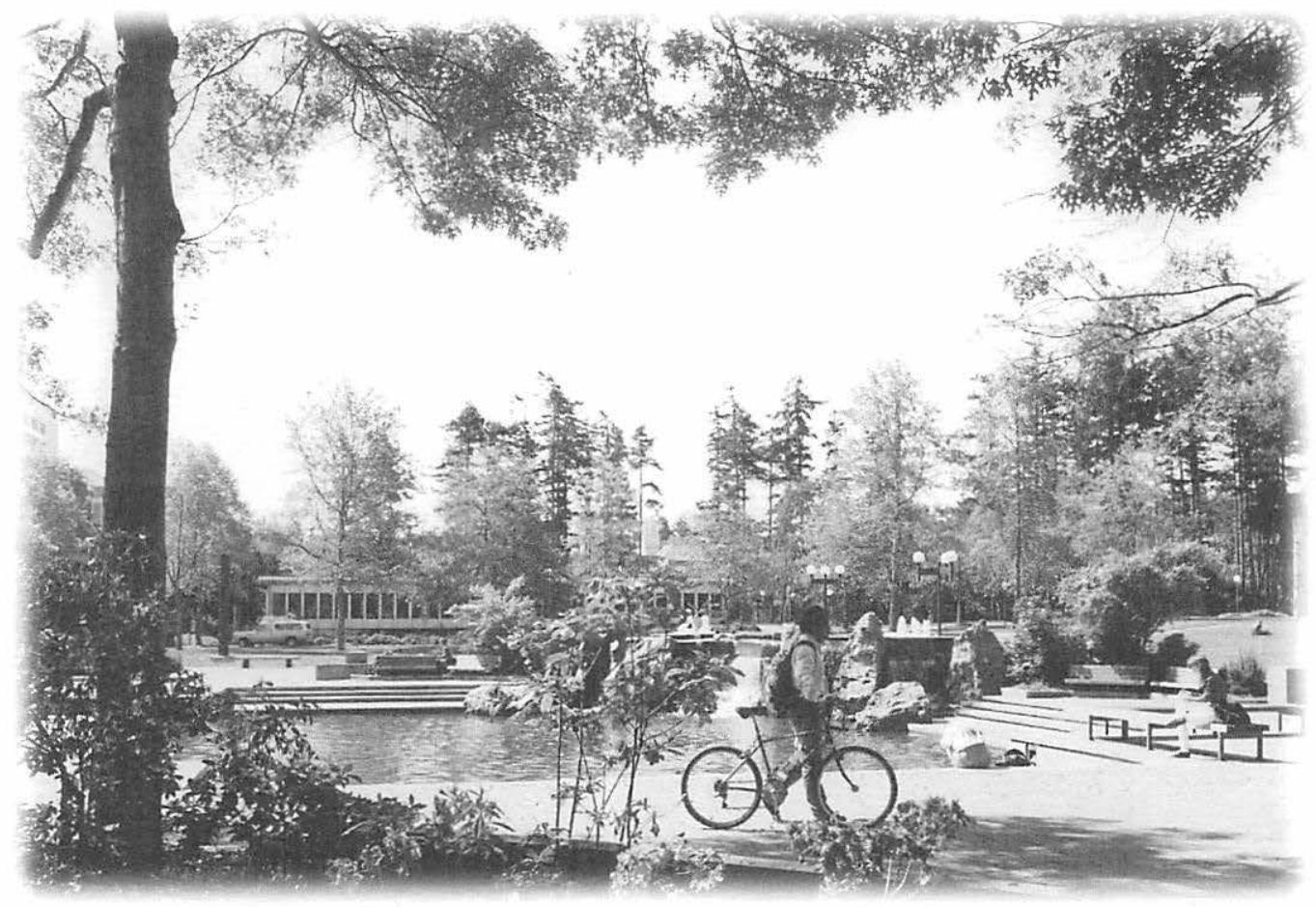

University of Victoria, site of FLEAT III/IALL '97. 